\title{
La rebelión criolla de la Villa de Oruro. Principales causas y perspectivas
}

\author{
José Óscar Frigerio
}

Buenos Aires, Argentina

Desde la frustrada rebelión de 1739, la villa minera de Oruro soportó continuas disputas de sus principales vecinos criollos con los españoles por el control de los primeros cargos del Cabildo, generándose dos bandos enfrentados. El conflicto se acentuó durante la década de 1760 al surgir el clan Rodríguez, que monopolizó los cargos capitulares sustentándose en su gran poder económico.

La década de 1770 presenció no sólo el aumento excesivo de las cargas fiscales $y$ del control burocrático real, sino una particular coyuntura de iliquidez de los mineros criollos que sería detonante de su rebelión en 1781. En confluencia con la sublevación general de Túpac Amaru, la rebelión de la villa entera liderada por los Rodríguez. dio como resultado la masacre y saqueo de un grupo de comerciantes españoles.

Oruro implico un incipiente polo de poder criollo, con la elaboración de una ideología nacionalista criolla, sustentada en justificaciones ideológicas y un limitado mesianismo. Su carencia de programa independentista produjo una alternancia ambigua de sus lideres criollos entre los polos enfrentados.

La presente investigación tiene por objetivo analizar las condiciones generales y particulares en que se desarrolló la rebelión de la "Real Villa de San Felipe de Austria y Asiento de Minas de Oruro", y zonas adyacentes sobre las que ésta poseía influencia, en el año 1781. Su originalidad y condiciones específicas han sido poco tenidas en cuenta por los estudiosos de las innumerables revueltas y rebeliones acaecidas durante el siglo XVIII en el Alto Perú, por lo que este estudio quiere destacar el comportamiento del grupo criollo que la encabezó, que en Oruro adquirió especiales características. *

La masa documental que al respecto se encuentra en el Archivo General de la Nación de Buenos Aires, Argentina, no se limita a los cuatro grandes legajos caratulados como "Sublevación de Oruro, 1781", sino

* Agradezco a los historiadores Eduardo Saguier, Enrique Tándeter, José Chiaramonte y el Instituto Ravignani (UBA), Félix Luna y la Revista "Todo es Historia", Guillermo Mira, y a los antropólogos Ana María Lorandi y el Instituto de Antropología (UBA), Salomón Frank y Sinclair Tompson, porque desde el "I Congreso Internacional de Etnohistoria" (Buenos Aires, 1989), en que presenté una aproximación de este tema, hasta el presente, colaboraron de alguna manera a esta publicación. 
que es relativamente voluminosa (unos 100 expedientes), debido a las necesidades legales planteadas por la maquinaria burocrática instrumentada por la Real Audiencia Pretorial de Buenos Aires para desarrollar la "Causa de Oruro", ' por orden de Carlos III y su delegado, el virrey Juan José de Vértiz y Salcedo a partir de 1784, cuando los acusados de ser sus principales cabecillas fueron trasladados a la capital del Virreinato del Río de la Plata.

Resulta difícil precisar las motivaciones que impulsaron a la corte española para instrumentar tan largo proceso judicial (1784-1801), situación sin precedentes en la gran sublevación general de 1780, en que los procesos a los acusados de las castas inferiores (indios, mestizos, cholos, mulatos, negros) fueron sumarísimos, con torturas y rápido desemboque en el patíbulo, mientras la actitud hacia los criollos fue cautelosa y contradictoria, siendo perdonados o recibiendo condenas mucho más leves los que participaron. ${ }^{2}$

La razón de tan excepcional proceso parece residir justamente en que los acusados eran criollos en su mayor parte, y tanto el efectivo poder que habían alcanzado como la crueldad y ambición atribuidas a la masacre y, más aún, la peligrosa alianza con las castas inferiores que la habría producido, movilizó a los españoles a intentar indagar sus alcances y motivaciones últimas.

A la postre, los resultados de la "Causa de Oruro" fueron estériles para España. Largos interrogatorios a los acusados y multitud de testigos, plantearon un laberinto carente del maravilloso "hilo de Ariadna". Parece evidente el mantenimiento de cierta fórmula legal y la ausencia de torturas ${ }^{3}$

1 Archivo General de la Nación, Buenos Aires (en adelante AGN), Temporalidades, 1785 1786, legajo 14. La "Causa de Oruro" fue solicitada al oidor de la Real Audiencia Pretorial de Buenos Aires, Francisco Garasa Giménez de Vázquez, quien actuó en carácter de "Juez Comisionado" por el rey Carlos III. Fue caratulada como "Crimen de Lesa Majestad" -equivalente al actual "AIta traición"- siendo catalogados los acusados como "reos de Estado", ordenando el virrey Vértiz. por su presunta peligrosidad la construcción de una cárcel especial en Buenos Aires, los llamados "calabozos de Oruro".

2 O'Phelan Godoy considera que la "estratégica y decisiva participación de los criollos no fue considerada en su real dimensión". Cfr. O'Phelan Godoy, Scarlett: Un siglo de Rebeliones Anticoloniales, Perú y Bolivia, 1700-1783, Cuzco, 1988, pág. 287.

3 Decimos "cierta fórmula legal" porque se permitió que los reos hicieran alegatos de sus situaciones penosas y porque al presbítero Mariano Bernal -que era abogado- se le permitió concretar su propia defensa cuando fue abandonado por su defensor. En cuanto a las torturas, sólo fueron consignadas en los expedientes durante la estancia de los reos en Potosí, por orden del gobernador intendente Juan del Pino Manrique. En Buenos Aires, hasta los carceleros fueron testigos favorables a la defensa. AGN, sala IX, legajo 2, expediente 7, Sublevación de Oruro, 1781; y AGN, s. IX, leg. 27, exp. 5, Interior, 1789. 
durante los interrogatorios en Buenos Aires, a pesar de las condiciones penosas que debieron soportar los reos en sus celdas que implicaron una coerción psicológica en sus declaraciones, motivando las contradicciones, acusaciones mutuas y desvaríos permanentes. Ello no objeta la riqueza innegable de este largo proceso judicial, cuestión en la que disentimos con Boleslao Lewin, quien adujo "razones comprensibles" (sic!) para prescindir de las declaraciones de los reos de Oruro sin fundamentar adecuadamente esa afirmación.

Aunque tras Lewin se evidencia la influencia ejercida por historiadores bolivianos (especialmente Adolfo Mier), disentimos con su justificación a ultranza de los criollos orureños. No puede ocultar su simpatía con la postura de los sublevados afirmando que la exclusión del seno del Cabildo de los criollos Rodríguez resultó impolítica, porque "los orureños de las capas superiores, los vecinos, se vieron atacados de frente por los españoles y empujados hacia la plebe", negando rotundamente su contacto con los sublevados tupamaristas. Su postura resalta que Jacinto Rodríguez y sus adláteres se vieron obligados a asumir la jefatura del alzamiento en contra de su voluntad, con el único objetivo de "evitar mayores excesos", librándolos de culpa y cargo en la conjura. ${ }^{4}$

Igualmente diferimos de otros autores: Burgos trata de mostrar al presbítero Mariano Bernal como una víctima inocente del sistema de opresión colonial, pero no analiza la rebelión; Valcárcel señala acertadamente que existieron una causa económica y otra de casta para la rebelión, pero parece ignorar el juicio llevado a cabo a los sublevados; Cornblit nos parece acertado en su caracterización de esta rebelión, aunque diferimos notoriamente en la metodología de análisis y en su designación de "clases sociales" a las que en esta investigación tipificamos como "castas"; ${ }^{5}$ Szeminski incurre en una generalización audaz debido a su falta de conocimiento profundo de esta rebelión, al afirmar que "entre las comunidades rurales bajo la influencia de Oruro, los rebeldes intentaban

4 Lewin, Boleslao: Túpac Amaru y los origenes de la emancipación americana, Buenos Aires, 1957, capítulo referido a la sublevación tupamarista-criolla de Oruro.

5 Respecto a caracterizar como "castas" los sectores actuantes, hemos seguido postulados de Alberto Flores Galindo, quien define que en el siglo XVIII, junto a un gran aumento del número de mestizos, se produjo una confusión y mayor comunicación entre las castas, por lo que esa división pareció quebrarse. Ese factor posibilitó un movimiento rebelde integrador compuesto por criollos, mestizos, mulatos e indios. Pero existían razones estructurales que impidieron la cabal formulación de una estructura de clases: estabilidad de las clases dominantes y una profunda fragmentación de las clases subalternas. Esto último producto de la fragmentación espacial de la sociedad 
crear un estado independiente con el Inca como soberano", mientras que en los hechos fue una fugaz alianza la gestada entre criollos e indios; Cajías concreta en 1983 un análisis carente de globalidad presentando sólo los objetivos de la masa indígena movilizada tras sus reivindicaciones parciales, aunque al presentar su tesis de doctorado en Sevilla (1987) logra un pormenorizado análisis de todas las vicisitudes de esta rebelión; sin embargo, la carencia de síntesis conspira muchas veces contra el resultado global de su trabajo, no dejando de ninguna manera agotadas las posibilidades de estudio del tema. ${ }^{6}$

\section{Características de la villa minera}

En medio de las dos estribaciones de la cordillera de los Andes que se abren al ingresar desde el norte al territorio altoperuano (actual Bolivia), se encuentra una región plana. Es una meseta elevada surcada por cerros aislados, denominada "altiplano" o "puna". La región está integrada por varias cuencas, entre las que resalta la cuenca de Oruro, ${ }^{7}$ que contiene al lago Poopó. Está bordeada por la serranía de Huayllamarca, que actúa como obstáculo al paso de los vientos húmedos procedentes del lago Poopó, y las mesetas de Chacarilla y Corocoro que son cortadas por el río Desaguadero (unión entre el lago Titicaca y el Poopó).

\footnotetext{
colonial peruana que impedía la emergencia de nuevos grupos sociales, bloqueaba el desarrollo de un mercado interno, era un obstáculo para la difusión del movimiento tupamarista y signo de la imposible unidad nacional. Flores Galindo cita sobre estas cuestiones a Karen Spalding, en "Túpac Amaru y la sublevación de 1780", en A. Flores Galindo (editor): Túpac Amaru. 1780. Antología, Lima, 1976, págs. 284 a 286; Flores Galindo, Alberto: "La nación como utopía: Túpac Amaru. 1780", en Revista Dehates en Sociología, n." 1, Lima, febrero 1977; Spalding, Karen: De indio a campesino, Lima, 1974, pág. 248; O’Phelan Godoy: Un siglo de rebeliones, pág. 266.

6 Burgos, Ramón: "Apuntes sobre la vida del presbítero don Mariano Bernal Lira y Ampuero", en La Revista de Buenos Aires, tomo XXIV, Buenos Aires, 1871: Valcárcel, Daniel: La rebelión de Túpac Amaru, México, 1965; Cornblit, Óscar: "Levantamientos de masas en Perú y Bolivia durante el siglo XVIII", en Tulio Halperín Donghi (editor): El ocaso del orden colonial en Hispanoamérica, Buenos Aires, 1978; Szeminski, Jan: La utopía tupamarista, Lima, 1984; Cajías de la Vega, Fernando: "Los objetivos de la revolución indígena de 1781: el caso de Oruro", en Revista Andina, tomo 1, n." 2, Cuzco, diciembre 1983; y del mismo: La sublevación tupacamarista de 178I en Oruro y las provincias aledañas: sublevación de indios y revuelta criolla. tesis de doctorado inédita. Sevilla, 1987.

7 El toponímico "Oruro" proviene de las voces "uru-uru" que significan "lugar donde nace la luz". Está vinculado a la etnia homónima y al lago así llamado (Uru-uru), a cuyas márgenes se fundó la villa de Oruro en el siglo XVI; en el siglo XVIII se había desecado y desaparecido.
} 
La más antigua población fundada por españoles en territorio altoperuano creció en la cuenca de Oruro. En 1535 nació Paria, pueblecito humilde por mucho tiempo hasta que se descubrieron ricos filones de plata en sus proximidades, dando surgimiento a una pujante población minera: en 1606 fue fundada la villa de San Felipe de Austria. Durante las dos décadas siguientes su producción argentífera fue floreciente, declinando luego para mantenerse estacionaria durante todo el resto del siglo. ${ }^{8}$

Próximos a Oruro se encuentran los cerros de San Cristóbal, Pie de Gallo y de la Flamenca, de donde se extraía la mayor parte de la plata producida en la región, e igualmente aportaban el Real de Minas de La Joya y la Ribera de Sepulturas; también Poopó, Antequera y Avicaya en el corregimiento de Paria, que dependían de esa caja. De Berenguela, en el corregimiento de Cochabamba, Uncia en el de Chayanta y Collquiri en el de Sica-Sica, se obtenía estaño y otros minerales, y a veces plata. Las vetas argentíferas de los cerros orureños estaban rodeadas por todas partes de oro "purísimo", labrado desde antiguo."

Oruro seguía a Potosí en rango, por la calidad y cantidad de su producción minera en el Alto Perú, y era sede de una Caja Real. Siendo que la plata se "beneficiaba" con ganancia cuando acudía "de dos onzas para arriba de metal" por quintal, en Oruro durante el siglo XVII "se beneficiaban metales de a 8 onzas por quintal, y a veces treinta marcos por quintal". 10

La villa estaba situada en medio de una dilatada pampa, en su mayor parte salitrosa y cenagosa, donde crecían pastos ralos y duros. Los principales bastimentos provenían del fértil valle de Cochabamba, así como de Potosí, aunque el azúcar, vino y otras bebidas, y también las aceitunas, pasas y almendras venían desde grandes distancias. Una falta importante fue la escasez de agua para moler el mineral, debido a lo cual fue necesario dejar de explotar un cerro próximo a la población porque no

8 Vázquè Machicado, José: Catailogo referente a documentos de Oruro en el Archivo General de Indias de Sevilla, Oruro, 1966.

9 AGN, s. IX, legajo n." 1. Oruro, 1745-1781; Alonso Barba, Álvaro: Arte de los Metales, la Paz, 1939, pág. 47; Bargalló, Modesto: La minería y la metalurgia én la América Essañola durante la época colonial. México, 1955, pág. 221.

10 Fisher, John: Minas y mineros en el Perú Colonial (1776-1824). Lima, 1977; Relacione's Géográficas de Indias, Perú, tomo II, Madrid, 1885, pág. CLII, apéndice IV; Bargalló, Modes(o: La mimería y la mélalurgia...; Céspedes del Castillo, Ciuillermo: Lima y Buenos Aires. Repercusiones económicas y politicas de la creacion del Virreinato del Rio de la Plata. Sevilla. 1947, págs. 22-23. 
podía costear su producción, o bien, conducir lo extraído a las riberas cercanas que sí poseían agua. Lamentablemente esta solución era muy costosa, y la pérdida para los mineros considerable. "

A mediados del siglo XVIII, Oruro posé́a como principal componente de su población urbana una elevada proporción de mestizos e indios forasteros. Los mestizos orureños pertenecían en su mayor parte a la casta de los "cholos", quienes, al igual que los primeros, no pagaban tributo ni tenían obligación de mitar. Para caracterizarlos nos parece acertada la definición de Spalding, al decir que el cholo era una mezcla de mestizo e indio, poseyendo sólo un cuarto de ancestro español. ${ }^{12}$

En el momento de la rebelión, la mayoría de la población de la villa era mestiza. Los españoles europeos, despectivamente llamados chapetones, eran muy pocos y también los criollos eran minoritarios, siendo dudoso que todos fueran de sangre blanca pura. El grupo criollo orureño "se identificaba por su nacimiento en América, por su situación económica y por los cargos civiles y militares de jerarquía que ocupaban". ${ }^{13}$

En cuanto a la población indígena de Oruro, en el siglo XVIII estaba concentrada en cuatro repartimientos: San Felipe de Austria, San Ildefonso de Paria, Santa Bárbara de Sepulturas y el Asiento de La Joya. El primero, ubicado en la misma villa, comprendía el barrio de jornaleros mineros (coyarunas) llamado "La Ranchería", incluyendo indios yanaconas que trabajaban como empleados domésticos. Los otros tres repartimientos estaban en proximidades de la villa, con importante composición de jornaleros mineros libres.

Cajías asevera que la totalidad de los cuatro repartimientos indígenas de Oruro eran "forasteros sin tierra". En 1754 el censo del virrey conde de Superunda consignó 1.399 indios tributarios forasteros sobre un total de 4.426 indios habitantes de Oruro, quienes representaban el $24 \%$ de la población total; entre ellos no había ningún indio tributario originario. Vale decir que la mayor parte del territorio de la provincia de Oruro estaba en manos de criollos y europeos, bajo la forma de haciendas y estancias. ${ }^{14}$

11 Concolorcorvo: Lazarillo de ciegos caminantes, desde Buenos aires hasta Lima, 1773, Buenos Aires, 1942, págs. 232 a 237.

12 En realidad, la que Spalding expone es la definición fiscal colonial española. Spalding, K.: De indio..., pág. 166.

13 Cajías, F.: La sublevación tupacumarista de 1781 en Oruro..., págs. 60.

14 Ibídem, págs. 55-58; Golte, Jürgen: Reparos y reheliones. Túpac Amaru y las contradicciones de la economía colonial, Lima, 1980, págs. 54-55. 
La causa de la gran cantidad de indios forasteros no residía sólo en las migraciones voluntarias frecuentes, sino en la composición étnica de la población indígena de la región, porque desde tiempos prehispánicos la etnia aymara había dominado y subordinado a la etnia uru, bajo el status de yanaconas. Los urus conformaban comunidades muy pobres, generalmente de economía pescadora, instalados en zonas lacustres (alrededor de los lagos Titicaca, Uru-Uru y Poopó) y a lo largo de los ríos (Desaguadero). Como eran mucho más pobres que los aymaras, el tributo que pagaban estaba en la misma relación. Posteriormente aparecerían en las estadísticas coloniales como "forasteros sin tierra", "agregados" o "yanaconas", a los que se equiparaba por tributar mucho menos que un originario y no poseer tierras. Wachtel señala la presencia de urus en la provincia de Paria desde muy antiguo, quienes se hallaban muy gustosos trabajando como jornaleros libres en las minas orureñas. En el siglo XVIII una gran parte sufría procesos de aymarización. ${ }^{15}$

\section{Causas de la rebelión de $\mathbf{1 7 8 1}$}

Existieron desde comienzos del siglo XVIII condiciones que conducían en Oruro hacia un alzamiento contra la explotación colonial. El primer antecedente de importancia se sitúa en la conspiración del criollo Juan Vélez de Córdova, delatada en 1739. Se reivindicaba en ella por igual a criollos, mestizos e indios, siendo resultado de que no sólo pagaban tributos los últimos, mitando penosamente en Potosí y Huancavelica, sino que también se quería obligar a criollos y mestizos a pagar tributos como había ocurrido en Cochabamba en 1730. ${ }^{16}$

A partir de allí la villa soportó continuas disputas de vecinos criollos, entre sí y con los españoles. Generalmente se trataba de aquellos vecinos principales que accedían por su fortuna y prestigio a los cargos capitulares, implicando una manera de controlar la villa. Lewinski la de-

15 Golte, J.: Repartos y rebeliones, págs. 57-59; Bouysse-Cassagne, Théresé: "Pertenencia étnica, status económico y lenguas en Charcas a fines del siglo XVI", en Tasa de la Visita General de Francisco de Toledo, Lima, 1975; y de la misma: La identidad aymara. Aproximación histórica (siglo XV, siglo XVI). La Paz, 1987: Wachtel, Natan: Le retour des ancestres. Les indiens Urus de Bolivie XV-XVI siecle, París, 1990, págs. 480-482.

16 Según el "Manifiesto de Agravios"dado por la rebelión de Vélez de Córdova. Lewin, Boleslao: La rebelión de Túpac Amaru y los orígenes de la independencia de Hispanoamérica, Buenos Aires, 1967, pág. 119. 
fine como una situación de "revuelta latente y permanente". El origen de toda disputa residía en la elección de los alcaldes, porque cada favorecido votaba a parientes cercanos o amigos para que le secundaran, tendiendo a enfrentar al corregidor y sus parciales. ${ }^{17}$

La situación de enfrentamiento y disputa existente determinó el nombramiento directo de los alcaldes por las más altas autoridades virreinales, coincidiendo su ejecución con el extenso período virreinal del conde de Superunda (1745-1761). En estos años se intentó alejar a los criollos Melchor de Herrera y su hijo Manuel de Herrera de los cargos capitulares, mientras que a partir de 1762 se trató de resistir el creciente monopolio que ejercía la familia Rodríguez de Herrera. Hasta ese momento habían ocupado cargos importantes los hermanos Melchor y Lorenzo Rodríguez de Herrera. ${ }^{18}$

A partir de 1762 se entronizaron en el Cabildo orureño los hijos del mencionado Melchor Rodríguez, Jacinto y Juan de Dios, opulentos mineros y hacendados, usufructuando los principales cargos hasta 1779 - y luego de la rebelión de 1781 - junto a sus parientes, amigos, socios, sirvientes o compadres. No sólo poseyeron poder económico y político, sino incluso militar, ya que Jacinto Rodríguez fue nombrado teniente coronel de las milicias orureñas en 1771 - cuando el corregidor José del Castillo fue asesinado por los indios de Sica-Sica-, y Juan de Dios Rodríguez fue nombrado coronel en 1778. ${ }^{19}$

Como resultado de la gestación de este clan, en los años anteriores a 1781 los bandos aparecían relativamente bien diferenciados en Oruro: por un lado el corregidor, generalmente español de nacimiento, junto a una jerarquía de acaudalados comerciantes, y por otro, esa alianza de

17 Constantino Bayle asegura que "la reelección, como más tarde la compra, daba pie a que se enfeudasen en cortos grupos o familias los oficios de honra; lo mismo que el voto a parientes". Y pone como ejemplo a la familia Castro en Guayaquil, y la familia Millán-Vela, de Tocaima. Nueva Granada. Añade que en 1566 el gobernador del Perú García de Castro escribió de los alcaldes ordinarios de Indias "todo es entre compadres". Bayle, Constantino, S. I.: Los cabildos seculares en la América Española, Madrid, 1952, págs. 118-120; Lewinski, Liliana: Les places marchandes d'Oruro. Strategies commerciales et rapports de pouvoirs (XVIle-XXe Siecle), tesis doctoral inédita, París, 1987, pág. 26; AGN, s. IX, leg. n." I, Oruro, 1745-1781.

18 AGN, sala IX, legajo n." I. Oruro, 1745-1781. Melchor Rodríguez había sido alcalde de $1 .^{\circ}$ y 2." voto, y Lorenzo Rodríguez corregidor y justicia mayor de Paria en 1753.

19 Ibídem. Si bien el "compadrazgo" implica la vinculación que el padrino de una criatura contrae con los padres de ella, en este período las españoles le daban al término un sentido diferente, apareciendo "compadre" como sinónimo de "compinche", vale decir, asociado con fines de actos ilícitos o encubrimiento, indicando una relación personal de amistad o camaradería que posibilitaba la ayuda y defensa mutua contra el poder colonial. 
criollos, mineros y azogueros, hacendados, comerciantes y artesanos, que acaparaban los principales cargos capitulares. ${ }^{20}$

En la villa hubo frecuentes incidentes con los corregidores, funcionarios venales, insolentes y atropelladores, siempre endeudados con la Corona en los principales impuestos que recaudaban y haciendo gala de su poder gracias a las tropas milicianas bajo su mando. Antes de 1781 había notorios enfrentamientos con ellos, ya fuera por los repartos o por la elección de los alcaldes, cargos que recaían con mucha asiduidad en el clan Rodríguez, integrado por criollos poco adictos al corregidor de turno. Como ejemplo de estos enfrentamientos puede señalarse el intento de 1774 por parte de los alcaldes de querer abolir un privilegio antiguo de los corregidores: el impuesto anualmente pagado por los carniceros de carne de llama y los fabricantes de sebo. Igualmente en 1775 pidieron que cesara la "visita de Varas y Pesos" al comercio, por la que el corregidor podía exigir anualmente cuatro pesos de contribución. ${ }^{21}$

En 1772 aparecía otra cuestión sintomática de estos enfrentamientos. Una ordenanza gravaba a los comerciantes forasteros y también a "los de algún fuste" radicados en la villa, obligándolos a construir un altar para el festejo del Corpus. En 1775, Diego de Acero, juez diputado de Comercio, afirmaba que el nombrar altareros para el Corpus debía ser entendido como un acto voluntario, denunciando la "corruptela" que obligaba a "mucha pobre gente que se mantiene a expensas del crédito en el comercio con sus tiendas públicas" a sufragar otros altares, de modo que ese año concurría el comercio con tres de los siete altares del evento. Tal situación fue denunciada igualmente por un grupo de comerciantes criollos, vecinos de Oruro, puntualizando las "desigualdades" que se producían en el Gremio de Comercio debido a "una mezclada denominación de individuos", por lo que se vieron obligados como en años anteriores a concurrir a la festividad con otros gremios (carac-

20) Relativo al enfrentamiento entre criollos y peninsulares, durante la década de 1740 testigos presenciales afirmaron: "No deja de parecer cosa impropia...que entre gentes de una nación, de una misma religión, y aun de una misma sangre, haya tanta enemistad, encono y odio, como se observa en el Perú, donde las ciudades y poblaciones grandes son un teatro de discordias y de continua oposición entre españoles y criollos" (...) "Basta ser europeo o chapetón, como le llaman en el Perú, para declararse inmediatamente contrario a los criollos; y es suficiente el haber nacido en las Indias para aborrecer a los europeos..." Juan, Jorge, y Ulloa, Antonio de: Noticias Secretas de América, tomo II, Madrid, 1918, págs. 415-416.

21 Resulta evidente que había en todas partes problemas con los corregidores, a causa de sus notorios abusos en los repartos. AGN, s. IX, leg. n." 1, Oruro, 1745-1781. 
terizados como "bajos y mecánicos"), solicitando hacerlo en adelante en el que pertenecían. Los firmantes eran Nicolás Iriarte, Clemente Mena, Martín Mena, Pantaleón Martínez, José Azurduy Lasarte y su mujer, María Francisca Goya, Josefa Rodríguez de Arijón y Melchora Barroso (mujer de Miguel Portilla), una buena parte de los cuales, no por casualidad, van a ser involucrados luego como cabecillas de la rebelión orureña de 1781. 22

No sería para nada sorprendente que estos comerciantes criollos fueran afectados por el reparto de efectos, realizado por los corregidores. Golte asegura que ellos afectaron a la población criolla, mestiza y mulata de las provincias peruanas, siendo los mismos pequeños agricultores, hacendados, arrieros, comerciantes y artesanos, en su mayoría pobres, corriendo la misma suerte que los indios. Ello sólo habría ocurrido a partir de la década de 1770. ${ }^{2.3}$

Tampoco hemos encontrado rastros documentales que certifiquen la aplicación directa en Oruro de las medidas fiscales instrumentadas por el visitador Areche, y en los testimonios de la causa nunca se las menciona, aunque debieron aplicarse con toda seguridad y no podemos descartar que existiera un rechazo general a la aplicación de tales medidas. Cuestiones como el inusitado aumento del impuesto a la alcabala, los nuevos impuestos a la coca y el aguardiente - de uso tan extendido entre los trabajadores mineros-, las medidas destinadas a terminar con el contrabando de oro y plata impidiendo la circulación de piezas no previamente selladas y fundidas, la elevación del peaje para el transporte interno de mercaderías, y el censo de la población no indígena, con la posible inclusión de los cholos entre los tributarios, parecen haber influido directamente en la rebelión orureña de 1781. ${ }^{24}$

Además, según señala O'Phelan Godoy, a fines de 1777 se distribuyó una circular entre los corregidores de Chayanta, Paria, Oruro, Pacajes y La Paz para que no sólo realizaran el reparto forzoso de mercaderías y cobraran el tributo, sino igualmente cobraran las alcabalas. Ello añadiría un argumento más para que los mismos entraran en conflicto, no sólo

22 Ibídem.

23 Los que Golte caracteriza como "españoles", consideramos que son "españoles americanos", vale decir, criollos. Golte, J.: Repartos y reheliones, págs. 171-172.

24 Lewin. B.: La rebelión de Túpac Amaru...; Palacio Atard, Vicente: Areche y Guirior. Observaciones sobre el fracaso de una visita al Perú, Sevilla, 1946; O’Phelan Godoy, S.: Un siglo de rebeliones..., págs. 175-186; Golte, J.: Repartos y rebeliones, págs. 173-176. 
con los campesinos indígenas, sino también con los mestizos, mulatos y criollos, comerciantes, artesanos, mineros, arrieros y hacendados. ${ }^{25}$

\section{Endeudamiento de los mineros criollos}

Importantes especialistas en la historia de la minería peruana han demostrado que es inadecuado hablar de la crisis y decadencia de la misma durante la segunda mitad del siglo XVIII. Flores Galindo puntualiza que es censurable caer en el estereotipo de una minería en decadencia. O'Phelan Godoy, por su parte, asegura que durante ese siglo la producción en las minas de Potosí y el Alto Perú declinó, aunque si bien "experimentó una recesión durante la primera mitad del siglo XVIII, comenzó a mostrar notables signos de recuperación en el período posterior a 1770". La explicación residiría en un "reemplazo de la anterior concentración de recursos en Huancavelica y Potosí por un patrón de dispersión geográfica que estimuló la apertura de yacimientos alternativos...”. ${ }^{26}$

Sin embargo, a pesar de que resulta correcto hablar de la recuperación minera peruana en la segunda mitad del siglo XVIII, tal cuestión se ve relativizada porque: a) Las zonas productoras por excelencia en siglos anteriores (Potosí, Huancavelica) estaban en decadencia; b) Si bien un porcentaje importante de la producción aludida siguió dependiendo de Potosí, ello se explica por la riqueza excepcional de esa zona, aunque sea acertado afirmar que estaba en decadencia por cuanto el rico cerro nunca volvió a producir ni la mitad de lo que había dado durante su época de mayor auge, a finales del siglo XVI; c) Surgen otros centros productores situados en su mayor parte en el Bajo Perú: Pasco, Cailloma (Arequipa), el Nuevo Potosí (Huarochirí), Huantajaya (Tarapacá), Hualgayoc (Cajamarca) y Huallanca (Tarma). ${ }^{27}$

En cuanto a la minería orureña, los estudiosos afirman que resurgió después de 1740 gracias al descubrimiento de nuevas minas de plata en Poopó. Según estudios cuantitativos de Cajías, los ingresos de las Cajas Reales aumentaron gradualmente desde 1765 a 1779. En 1776 esos ingresos se triplicaron debido al aumento de la actividad minera (diezmos

25 O'Phelan Godoy: Un siglo de rebeliones.... pág. 182.

26 Flores Galindo, A.: "Túpac Amaru y la sublevación...", págs. 287-288; O’Phelan Godoy: Un siglo de rebeliones.... págs. 28-29.

27 O'Phelan Godoy: Un siglo de rebeliones... págs. 29-35. 
y venta de azogue). En ese año la producción de Oruro superó a la de Pasco, cuestión evidenciada en un mayor registro de marcos de plata fundidos, aunque el segundo centro superaba al primero en cuanto a los ingresos totales obtenidos por la Corona. ${ }^{28}$

Sin embargo, debemos puntualizar que la documentación encontrada sugiere una situación contradictoria entre el crecimiento de la producción minera y el estado económico de los mineros criollos orureños, situación al parecer bastante grave durante la década de 1770 debido a la falta de liquidez y las pérdidas que éstos sufrían, arrastrando tras de sí toda la economía lugareña y constituyéndose en una de las causas más importantes de la rebelión de 1781 .

Antes de entrar a analizar la particular coyuntura orureña, debemos señalar algunas cuestiones generales sobre los mineros peruanos y sus peculiares condiciones de producción. La mayoría de ellos eran pobres y casi sin recursos, los cuales se asociaban a algún cateador y denunciaban una de las minas que tenían reconocidas, o pedían la adjudicación de alguna despoblada, por compra o arriendo al rey. Con una muestra de los metales se dirigían a un aviador (habilitador o comerciante rescatador) ponderando la riqueza de la veta hallada, para lograr interesarlo a invertir en ella. Para convencerle muchas veces le ofrecían toda la piña que ella produjera, añadiendo que no necesitarían de mucho efectivo pues entre sus trabajadores distribuirían objetos en especie. Obtenido así el primer capital, luego irían solicitándole otros reembolsos necesarios para hacer producir la mina. Con todo, los riesgos eran muchos y se fracasaba con facilidad, siendo lugar común que la veta no rindiese los frutos esperados. ${ }^{29}$

Fisher igualmente asegura que en el último tercio del siglo XVIII los mineros peruanos dependían "de los créditos otorgados por los comerciantes, muchas veces en especie", a quienes debían recompensar con altos intereses y entregarles "el mineral obtenido a precios más bajos que los corrientes". Estaban obligados a depender de estos créditos para pagar los jornales de los operarios y adquirir los insumos impres-

28 Cajías de la Vega, Fernando: "La sublevación de indios de 1780-1781 y la Minería de Oruro", en Revista Historia y Cultura, n." 10, La Paz, octubre 1986, pág. 65; Cornblit, Óscar: "Levantamientos de masas...", pág. 76.

29 Ulloa, Antonio de: Noticias Americanas, Entretenimiento físico-histórico sobre la América Meridional y la Septentrional oriental, Buenos Aires, 1944, págs. 180-182. 
cindibles para la explotación: azogue, sal, estaño -que en Oruro servía de magistral-, pólvora, velas, coca, aguardiente, herramientas y comida. ${ }^{30}$

El comerciante local, generalmente español de nacimiento, que oficiaba de aviador, adelantaba dinero por períodos cortos - un mes, dos o tres a lo sumo- a cambio de obtener la piña - plata extraída después de la amalgamación por azogue, aunque sin acuñar - a precios mucho más bajos que los corrientes en plata. Lograban así crecidos beneficios a través de una "enorme usura". La experiencia había demostrado a los aviadores que los avíos a largo plazo nunca eran devueltos por los mineros criollos, cuestión que también influyó para que los grandes capitalistas "no mostraran gran inclinación en invertir" en la minería peruana. ${ }^{31}$

Debemos añadir que los mineros criollos peruanos gozaron durante la mayor parte del siglo de un gran desprestigio, pues eran considerados ignorantes, negligentes, despilfarradores, carentes de escrúpulos y eternos incumplidores de sus créditos. ${ }^{32}$

Respecto a la situación concreta por la que transitó Oruro en los años próximos a la rebelión, la documentación que hemos encontrado - si bien es limitada - señala que la minería orureña pasaba, al menos en la década de 1770 , por momentos sumamente difíciles, debido a que los principales mineros carecían de liquidez para pagar sus créditos y estaban cercanos a la quiebra. Tal situación parece haber sido en gran parte el resultado de que los comerciantes rescatadores (aviadores o habilitadores de capital) les habían retirado su aporte monetario, debido a la penuria en que aquéllos se encontraban y no poder cumplir con las obligaciones contraídas con éstos.

Así lo explicaba el padre mercedario José de Echevarría en su diario anónimo sobre la rebelión de Oruro, diciendo:

30 Fisher, J.: Minas y mineros..., págs. 14, 16, 46-47.

31 Ibídem, págs. 201, 203, 206-207.

32 Diversos testimonios prueban esta afirmación, entre ellos: En 1747, el visitador Herboso afirmaba que "sólo se obtenía un cuarto del contenido en plata de los minerales a causa de la ignorancia de los beneficiadores"; en 1783, Juan del Pino Manrique, gobernador intendente del Potosí, decía que la ruina de las minas estaba originada en la defectuosa explotación de que eran objeto, debido a la "crasa ignorancia de los mineros, siendo los azogueros "hombres ignorantísimos, llenos de vicios, conocidos de mala fe, tan faltos de instrucción que los más no saben leer...". Tándeter. Enrique: Coacción y Mercado. La minería de la plata en el Potosí colonial, 1692-1826. Buenos Aires, 1902, pág. 230; Cornblit: Levantamientos de masas..., pág. 76; Fisher: Minas y mineros..., pág. 82. 
"de diez años a esta parte se ha experimentado en esta villa un total atraso en las lavores de Minas de suerte que en la presente providencia no había una sola lavor que llevase formal trabajo, ni pudiese rendir aun lo necesario para su conservación y giro siendo éstas las únicas que sostenían al vecindario, cuya total decadencia ha puesto a sus Mineros y Azogueros, en tan lamentable constitución que los que se contaran por principales, y en otros tiempos poseyeran agigantados caudales como heran los referidos Rodríguez, Herrera y Galleguillos, con otros residentes, todos se hallan en un estado de inopia, descubiertos en muchos miles assí al Rey, como a otros particulares sin poderles pagar por no tener con que seguir el trabajo de sus lavores, porque los habilitadores de estos que regularmente y aun diré que únicamente eran los chapetones, ya no querían hacerles el mismo suplemento pues muchos de ellos habían quebrado por socorrer a dichos Mineros, quienes desesperados por no tener con que trabajar, no hallando otro medio de socorrerse, y chancelar sus deudas con los chapetones, parece maquinaron esta rebelión". 33

\section{Y con el mismo sentido, otro cronista anónimo comenta:}

"Y en fin cuanto beneficio/ habeis poseído y gozado/ ha sido por europeos/ esto no podéis negarlo./ Igualmente los presentes/ a quien habeis martirizado/ cuantas vezes os fiaban/ sus caudales sin reparos/ cuantas avilitaciones/ os hacían en el año/ para que buenas labores/ de minas rindiesen algo?/ Y si no fuera por ellos/ de donde hubiérais sacado/ para buestras fantasías/ de besamanos y regalos?/ Lo cierto y evidente es/ que lo que mérito ha dado/ a tanto aborrecimiento/ ha sido haber retirado/ los auxilios y socorros/ conque os iban tomando./ Mas si esto fue delito/ de qué ha sido originado?/ de vuestro propio defecto/ y el haber siempre aspirado/ a quedaros con lo ajeno/ y no pagar lo prestado". ${ }^{34}$

También existen testimonios de dos corregidores de Oruro, quienes aseguraban que su corregimiento pasaba por momentos penosos: Juan Gelly planteaba en 1773: "Los intereses que ofrece este Corregimiento son tan escasos por la exterminada constitución en que se hallan sus minas, y por el consiguiente sus vecinos, que sus resultas de Congrua no

33 Anónimo, "Diario del Tumulto acaecido en la Villa de Oruro en 10 de Febrero de 1781 con motivo de la sublevación de Tupaj Amaru", en La Revista de Buenos Aires, n." 87, t. XXII, Buenos Aires, julio de 1870, pág. 337. Existen dos copias manuscritas en AGN, s. IX, Túpac Amaru. Documentos sueltos sobre su proceso, y otra en AGN, s. IX, Rebelión de José Túpac Amaru en el Perú.

34 Anónimo, "Romance y relación hecha en la Villa de Cochabamba en repulsa de las iniquas acusaciones con que los sublevados orureños intentan dar contra los europeos, según se ve en la antecedente obra, en que se expresan todos los sucesos acaecidos la noche del día lo de Febrero de este año de 1781 anteriores y sinsequentes", en AGN, s. IX. Túpac Amaru. Documentos sueltos. 
son capaces de subsanar la más escasa manutención aún en lo preciso..."; y Joaquín de Alós en 1777, fundamentaba su necesidad de ser trasladado de corregimiento, por cuanto en Oruro se había desengañado de que "absolutamente podía ni mantenerme en él, por ser el más ynfeliz de todo este Reino...”. 35

Igualmente una cuestión acuciante habría sido el deterioro que hacia 1776-1777 sufrían las herramientas de hierro usadas por los mineros en el laboreo de las minas, no sólo en Oruro sino en toda la región altoperuana. No habiendo llegado nuevas herramientas de repuesto en los navíos de registro del Callao, podrían parar todas las minas por falta tan esencial. Se las solicitó en Lima y se libró despacho a Jujuy para que hiciesen transportar toda la ferretería que hubiese, debido a que la carestía era general. ${ }^{36}$

En 1777, los miembros del Cabildo orureño encabezados por el alcalde de primer voto, teniente coronel de milicias y regidor decano de Oruro, Jacinto Rodríguez, afirmaban la falsedad de algunas acusaciones formuladas contra el contador de las Reales Cajas, Blas Gascón, pues "a él sólo se debe la subsistencia de esta villa, y sus minerales, a causa de que estos han venido a grande decadencia, y que si él no hubiera sostenido con su mucho fomento a los Mineros, ninguno hubiese podido, ni pudiera continuar el trabajo, todo sin interés ninguno". ${ }^{37}$

Poco tiempo después, el mencionado contador Blas Gascón, junto al tesorero Salvador Parrilla, elevaban un singular informe al visitador general José Antonio de Areche el 19 de octubre de 1777. En él se encuentran algunas importantes claves para comprender la situación real de la minería orureña y las dificultades de los mineros criollos. Cabe destacar que relativo a la crisis aparece una afirmación contradictoria, que también puede ser producto de las profundas divergencias que separaban a ambos funcionarios de las Reales Cajas de Oruro, el primero más proclive a los mineros criollos y el segundo enemistado con ellos y amigo del corregidor:

“...uno de los puntos que constituye al Reyno en el más deplorable estado es el espíritu que predomina de no querer pagar, o no pagar con puntualidad los que deben, perdiéndose infinitos créditos por este motivo...". ${ }^{38}$

35 AGN, Oruro, 1745-1781, leg. 1.

36 AGN, s. IX, La Paz, varios pueblos.

37 AGN, Oruro, 1745-1781, leg. 1.

38 Ibídem. 
Sin embargo, a pesar de insinuar la posibilidad de que los mineros no quisieran pagar sus débitos o no lo hicieran con puntualidad, aseguraban:

"...la rápida decadencia a que va caminando el Reyno; que todos los gremios, exercicios y clases de gentes se van atrasando aceleradamente e imposibilitando de poder pagar, ya sean Censos, o qualquier otra naturaleza de deudas, de suerte que toda especie de acreedores está expuesta a perder su caudal [...] la mayor parte de las gentes subsiste hoy con sólo el crédito de su giro y trabajo...".

Inmediatamente los funcionarios enumeraban las principales causas que impedían al minero pagar sus deudas o atrasaban su pago, insistiendo en la necesidad de "ayudarlo, fomentarlo y protegerlo para que pueda pagar...". Ellas residirían esencialmente en el comercio del azogue, tanto por el precio al que los mineros debían pagarlo como por una serie de providencias para adquirirlo. Así, por el azogue de Huancavelica los mineros orureños se quejaban de tener que pagar 97 pesos y 10 centavos por quintal, incluyendo el costo del quinto real del azogue -el cual no era pagado por los mineros de Huancavelica-, el "synodo y salarios Huancavelica", y hasta el derecho del "Buscón", que ni siquiera sabían qué era. Además, para adquirirlo estaban sujetos a ordenanzas estrictas, en cuanto a que no se les diese azogue fiado - sino que debían consignar como "seguro" prendas (alhajas generalmente) de oro y plata- ni todo el que quisieran, no pudiendo excederse de diez quintales al mes cada uno, sin otra razón que el pronto agotamiento de la mina de Huancavelica. ${ }^{39}$

Los funcionarios aseguraban que si el minero tenía "buenos metales y veta conocida" no se le podía dejar de fiar el azogue; y que el mandar lo aseguraran con prendas de oro y plata era "lo mismo que mandar que cerrasen las Minas y los Ingenios", porque no había ninguno que tuviera todo el oro y la plata necesarias. Por ello habían permitido que unos mineros adquirieran el azogue bajo el seguro de prendas de oro, plata, perlas, diamantes, otros otorgando escritura con hipoteca de todos sus bienes, y otros con fiadores; los menos lo pagaban al contado.

39) La escase\% de azogue era una amenaza permanente que pendía sobre las minas peruatnas. Huancavelica estaba en decadencia, y para compensar su falla de producción se debió recurrir al azogue de Almadén (España). ACN, Oruro, 174.5-1781: Cajías: "La sublevación de indios...". pág. 69. 
Añadían que existían otras cuestiones que afectaban a la minería de la zona: en primer lugar, que el que hacía el registro de una mina se solía apoderar de la mayor parte de las estacas con el nombre de otros; que se adjudicaban cerros enteros, minas y socavones, sin pregones y en virtud de un simple escrito; y que el que tenía muchas minas, ni las trabajaba todas ni las dejaba trabajar a otros,

"pretendiendo que con una sola que trabaje, quedan amparadas todas las demás (...) pues hay varias personas que con sus empleos y poder tienen estancados los Minerales, y no dejan trabajar a los pobres, los quales por la experiencia de que luego les arrebatan las Minas, no descubren ni catean...".

\section{Gascón y Parrilla hacían resaltar especialmente que}

"una de las principales causas por que se ha despoblado en el Reyno tantos Minerales que han sido tan ricos y opulentos, ha sido por no haberse querido aflojar un poco en las enunciadas providencias, y en el precio, por cuyo motivo no han podido trabajar los hombres".

\section{Desarrollo de la rebelión, justificaciones ideológicas y conflicto entre castas}

En la Villa de Oruro los hechos se precipitaron a partir de 1780. Variados sucesos encadenados, colaboraron al estallido de la rebelión: Desde fines de 1780 comenzaron a aparecer en ella pasquines idénticos a los del Cuzco, reivindicando a Túpac Amaru y anunciando su próximo gobierno, lo que ponía en evidencia la presencia de secuaces. El 16 de enero - poco tiempo después de la ejecución de Tomás Catari- fue asesinado el corregidor de Paria, Manuel de la Bodega, por los indios de Challapata cuando intentaba cobrar su tercer reparto de mercancías, y otro tanto ocurrió el 26 de enero con el corregidor de Carangas, Matías Ybáñez. Como los indios de las comarcas próximas estaban sublevados incluso antes de estos sucesos, en la villa se había dispuesto el reequipamiento y puesta en funcionamiento de las milicias urbanas, pertrechándose más de 300 milicianos mayoritariamente cholos, quienes realizaron adiestramiento permanente. Como se comenzó a temer un pronto ataque de los indios de Challapata debido a la presunta ayuda prestada por el corregidor Urrutia a Bodega cuando iba a cobrar su reparto, se extremaron las medidas de seguridad. En ese momento llegaron a Oruro dos 
acaudalados comerciantes chapetones, José de Endeyza y Juan Blanco, portando importante cantidad de piñas y barras de plata, oro y efectos de Castilla. Guareciéronse en la casa apodada "El Fuerte", yendo a refugiarse con ellos otros comerciantes españoles - algunos vecinos de la villa y otros forasteros - con sus caudales, al temerse una invasión de los indios sublevados. ${ }^{40}$

Puede detectarse la elaboración de justificaciones ideológicas en los días inmediatos al 10 de febrero de 1781, los que determinaron la masacre del grupo de comerciantes chapetones aludido. Tales justificaciones afirmaban centralmente que los criollos y los cholos (plebe mestiza) se rebelaron y asesinaron a los chapetones como autodefensa, pues éstos planeaban asesinarlos. Los días anteriòres al 10 de febrero los rumores al respecto se habían esparcido velozmente, quedando la población entera presa del pánico. Se generó una verdadera psicosis colectiva que estalló la primera noche de masacre, siendo inmisericordemente sacrificados los chapetones, obligados a salir por el incendio de su reducto. Las armas utilizadas por los conjurados fueron las usuales: palos, piedras, hondas y cuchillos. Arcabuces sólo de parte de los chapetones. ${ }^{41}$

Los testimonios de la "Causa de Oruro" explicitan cuáles fueron los principales rumores que alborotaron la plebe acuartelada, la que unida a otros sectores de la población concretaría el ataque. En primer término se señalaba un problema de casta, por cuanto se temía que las castas inferiores se unieran - por su vinculación racial y social- contra las superiores. Las voces señalaban que el español Francisco Santelices había dicho que era capaz de entregar a los cholos degollados como corderos. Igualmente se decía que el aludido, junto a José Cavallero y un tal Bullayn, afirmaban que antes que los cholos se juntaran con los indios, les cortarían las orejas. Por eso, el corregidor saliente Bentura Ayarza habría aconsejado al corregidor Urrutia que retirara las armas de fuego a

40 Anónimo, "Diario del Tumulto...", págs. 323-328; Frigerio, José Óscar: "Crimen y castigo en el Virreinato. La sublevación de Oruro de 1781 y su terrible represión", en Revista Todo es Historia, n." 196, Buenos Aires, septiembre 1983, págs. 61-62.

41 Las hemos tipificado como elaboraciones ideológicas debido a su carácter de altamente subjetivas, con una cuota importante de ilusiones o idealizaciones respecto a su propio comportamiento y al de las otras castas, resultando imposible diferenciar en ellas contenidos verdaderos de falsos, al no poder ser cotejados mayoritariamente con su praxis social. Raymond Ruyer define: "Una ideología es una seudo-teoría, que es en realidad un arma y la expresión de una voluntad colectiva de justificación o de propaganda", en su obra: "Caracteres generales de las utopías sociales", Irving Louis Horowitz (director): Historia y elementos de la sociología del conocimiento, capítulo X, tomo II, Buenos Aires, 1979, pág. 121. 
los cholos, al menos en el momento de una invasión de indios, porque de lo contrario deberían luchar con dos enemigos. ${ }^{42}$

La psicosis colectiva se precipitó a partir del 9 de febrero, cuando comenzó a cundir el pánico entre los familiares de los acuartelados, quienes presumiblemente estaban desarmados. Las mujeres, amigos y parientes comenzaron a pasarles cuchillos, imprecándoles a defenderse del regimiento de pardos, comandados por el tenebroso Francisco Santelices, quienes serían los ejecutores del degüello durante la noche. Con ese objeto, los negros - se decía - habían sido armados con dos cuchillos cada uno y su correspondiente escudo (broquel). Durante esa noche también hubo quien vio escaleras dispuestas desde la casa del corregidor hacia el cuartel y cartuchos preparados para concretar el ataque a los cholos. Se habló inclusive de un socavón excavado desde la casa del corregidor para hacerlos volar con pólvora, pero su existencia no fue certificada por el escribano José Manuel Montesinos tiempo más tarde, poniendo en peligro su propia vida al negarse al hablar. ${ }^{43}$

Aun cuando puede notarse que la fantasía colectiva había cobrado vuelo, estos rumores pueden resultar mucho más verosímiles que otros -notoriamente falsos y malintencionados- que escondían el propósito político de exacerbar el enfrentamiento entre los chapetones y las castas inferiores. Según testimonios, fray Bernardino Gallegos había asegurado en esos días que había sido arrasada la ciudad de La Plata; que en Potosí "mataron a los Chapetones los indios de mita unidos, y confederados con muchos Criollos y los Cagchas". Añadiendo que en La Paz "havían querido los Chapetones executar la misma traición que en Oruro, pero que con el mismo Socabón que ellos havían hecho, o minado para este efecto, murieron en el Quartel 200 chapetones y 30 criollos". Y para animar a los amotinados durante la primera noche de rebelión daban voces por las calles, diciendo: "Ea criollos, criollos, acarreen piedras para matar a los Chapetones pues ellos han sido enemigos de nuestras vidas, ya le quitaron la cabeza a D. Jacinto Rodríguez, y otros ya han muerto 30 , nuestros paisanos los criollos". Días después, al entrar Diego Flores ca-

42 Existe la posibilidad de que este Francisco Santelices sea el mismo que menciona Siles, y por lo tanto tendría ya antecedentes anticriollos y antimestizos por cuanto en 1772, habría integrado una milicia de comerciantes chapetones que se negaron a formar parte de las milicias urbanas "no queriendo mezclarse con cholos ni criollos". AGN, Sublevación de Oruro, 1781, legajo 1, exp. 1: anónimo, "Diario del Tumulto...", págs. 332-333; Valle de Siles, María Eugenia del: Historia de la rébelión de Túpac Catari, 1781-1782, La Paz, 1990, págs. 549-550.

43 AGN, Sublevación de Oruro, 1781, legajo 1 y 2 ; anónimo, "Diario del Tumulto...", págs. 332-333; Frigerio, "Crimen y castigo...", págs. 62-6.3 y 76. 
pitaneando una bandada de indios de Sora-Sora, había asegurado a Clemente Menacho y Miguel Portilla al recibirlos que Túpac Amaru "ya había tomado posesión de la Ciudad de La Paz, y muerto más de quatrocientos chapetones, porque ahí havían intentado la misma traición que en Oruro....". ${ }^{44}$

Los pormenores de la rebelión fueron reflejados de manera sumamente contradictoria según hubiera sido el declarante testigo presencial o no de los hechos, según su participación y la intencionalidad que lo moviera, y de acuerdo al condicionamiento social, vale decir, la casta a la que perteneciera. Intentaremos sintetizar las cuestiones más importantes, privilegiando la participación o el enfrentamiento de las castas.

Los testimonios de españoles generalmente sindicaron como autores del amotinamiento a los criollos secundados por los cholos, mulatos e indios yanaconas, puntualizándose también que en la primera noche de masacre no participaron los indios comarcanos rebelados, como se quiso hacer en primera instancia. Sin embargo, los criollos, acusados de ser ideólogos de esta rebelión, se defendieron acusando centralmente a la plebe mestiza, y otros estratos socialmente bajos como "los indios forasteros traficantes" o "los Texedores cochabambinos", quienes se habrían dejado ganar por la ambición de apoderarse de los muchos caudales reunidos por los Chapetones. ${ }^{45}$

Los indios rebelados de las comarcas próximas entraron en gran número a la villa a partir del día siguiente, uniéndose a los conjurados en ella para descubrir los chapetones que aún estaban escondidos y con vida. Asaltaron las casas y comercios de los chapetones, y los templos y conventos donde habrían encontrado seguro refugio. Si bien se señaló que muchos criollos participantes habrían dirigido a los alzados, el principal líder de los cholos sería Clemente Menacho mientras que Diego Flores lo habría sido de los indios. El único lugar donde los indios no entraban y que gozaba de completa inmunidad era la casa de los Rodríguez, y también eventualmente la de Manuel de Herrera. ${ }^{46}$

44 Anónimo, "Diario del Tumulto...", págs. 341 y 357; AGN, s. IX, Sublevación de Oruro, 1781, legajo 2, exp. 7 .

45 AGN, Sublevación de Oruro, 1781, s. IX, legajo 3, "Sumaria Secreta de la rebelión de Oruro"; s. IX, legajo I, "Primer cuaderno de confesiones".

46 AGN, Túpac Amaru. Documentos sueltos, s. IX, "Noticias de La Plata, Oruro, Paria, Carangas y demás provincias del reino, recibidas del Correo General del mes de abril de 1781"; AGN, Sublevación de Oruro, 1781, legajos 1 y 2; confesiones de los reos; Colección Documental de la Independencia del Perú, tomo II, vol. 2, documentos núms. 151, 161, 162, 176; AGN, Interior, s. IX, legajo 27, exp. 5. 
La alianza que se estableció con los criollos y cholos limitó en principio la ferocidad de los indios invasores - parece que lo que más influyó fueron las conciliadoras consignas de Túpac Amaru- por cuanto si bien profanaron los templos y conventos buscando chapetones y masacrándoles cuando los hallaron, no tocaron sus mujeres e hijos que estaban a su lado, ni a los curas. Cuestión similar había sucedido en la batalla de Sangarará, donde Túpac Amaru quiso hacer salir de la iglesia sitiada a los criollos y las mujeres, aunque éstos en su mayor parte perecieran por mano de los españoles en la confusión que se generó. ${ }^{47}$

La entrada de Diego Flores a Oruro, vestido con hunco, chuspa y montera, a la usanza india, capitaneando una bandada de indios de SoraSora, habría dado lugar a que todos los vecinos de la villa se vistieran como indios. Otra versión indicaba que tal cuestión había sido ordenada por Jacinto Rodríguez, electo como justicia mayor de Oruro, y la mujer de Clemente Menacho, María Quiroz. Algunas declaraciones afirmaron que únicamente el mencionado lucía un traje de terciopelo negro con sobrepuesto de plata, por lo que se consideraba que era virrey de Túpac Amaru. ${ }^{48}$

El primer enfrentamiento entre los criollos y los indios fue por los caudales de las Reales Cajas, que los indios reclamaron como propios al ser fruto del repartimiento y el tributo. Fue ultimado por defenderlas en un confuso episodio el criollo Sebastián Pagador, quien contradictoriamente era sindicado como representante de Túpac Amaru en Oruro. Ello obligó en principio a Jacinto Rodríguez a proclamarse como depositario de esos caudales hasta la llegada de Túpac Amaru a la villa, y luego a repartirles unos 25.000 pesos de plata, en un fallido intento por lograr su retirada. ${ }^{49}$

La preocupación de los indios por el reparto de las tierras comenzó en el momento de repartirles los zurrones de plata. Los indios "preguntaban si las tierras de los Españoles heran todas pertenecientes al

47 Ibídem; Mendiburu, Manuel de: Diccionario Histórico Biográfico del Perú, tomo XI, Lima, 1934, ver Túpac-Amaru, pág. 53.

48 AGN, Sublevación de Oruro, 1781, legajo 1, primer y segundo cuaderno de confesiones; anónimo, "Diario del Tumulto...", págs. 354.

49 AGN, Sublevación de Oruro, 1781, s. IX, leg. 1; anónimo, "Diario del Tumulto...", pág. 352; anónimo, "Relación de los horribles estragos que en el día 10 de febrero de 1781 hicieron los cholos e yndios en Oruro", en Colección Documental de la Independencia del Perú (en adelante, CDIP), t. II, vol. 2, doc. n." 151. Coincido con Cajías (La sublevación tupacamarista, pág. 467) cuando afirma que Sebastián Pagador no fue el protagonista principal del levantamiento del 10 de febrero, sino que lo fue "el pueblo en su conjunto". 
común de los indios; se les respondía que sí, añadían que ya no havían de pagar tributos, Diezmos, ni Premicias...". Luego, con la llegada de Juan de Dios Rodríguez en compañía de caciques de Challapata, “...todo el tiempo que se mantuvieron en ésta se ocuparon en pedir con despotismo a los hacendados de la Villa, cesiones y renuncias de sus haciendas para su comunidad...". ${ }^{50}$

Insolentados los indios con los criollos, como no encontraban más chapetones que matar y saquear, comenzaron a atacar sus propiedades e incluso mataron alguno de ellos, por lo que Juan de Dios Rodríguez, junto al cacique de Challapata, Lope Chungara, dieron la orden de echarlos de la villa, cuestión que lograron gracias al apoyo de la plebe mestiza. Luego se produjo el enfrentamiento entre los criollos y la plebe por el control de los caudales robados, triunfando los primeros gracias a la ejecución del principal líder de ésta.

La etapa de ruptura y enfrentamiento bélico entre los indios y los criollos y la plebe orureña se caracterizó por una gradación en las consignas planteadas por las comunidades que atacaron la villa. Los dos primeros ataques a la villa fueron liderados por las comunidades más pobres y atrasadas (Paria, Sillota y Challacollo), guiadas por consignas inmediatistas: un fuerte sentimiento de venganza - especialmente contra los Rodríguez-, y un ansia desmedida de rapiña. El tercer ataque fue liderado por la comunidad de Challapata — cuando ya habían asesinado al cacique Chungara-, mucho más avanzada en sus consignas, vale decir más consciente de sus intereses a largo plazo. Su líder, Santos Mamani, afirmó que había llegado el tiempo de aniquilar a los españoles y criollos, "porque ellos sin pensiones ni mayor trabajo eran dueños de lo que ellos travajaban bajo del yugo y apensionados con muchísimas cargas, y aquellos logravan de las comodidades y los Indios toda la vida estaban oprimidos, aperreados y constituidos en total desdicha". ${ }^{51}$

Se abrió una nueva etapa cuando, después de derrotados por una alianza de criollos, plebe mestiza —a quienes se habían unido los chapetones sobrevivientes que habían sido indultados-, los indios de mu-

50 Anónimo, "Diario del Tumulto", págs. 353 y 355.

51 Ibídem, pág. 355; Cajías, "Los objetivos de la revolución...", págs. 416-425; AGN, Sublevación de Oruro, 1781, leg. 2, exp. I bis. Santos Mamani, cabeza de la comunidad de Challapata, había liderado las invasiones a Arque y Tapacari, donde fueron masacrados por igual españoles. criollos y mestizos; hombres, mujeres y niños. El mestizo Patricio Figueroa declaró que era su orden que después de la destrucción de Oruro "habían de quedar por del común los Ingenios y Minas, y havía de seguir el trabajo de su cuenta con la Plata (y) azogues de la Caja Real...". 
chas comunidades cercanas comenzaron a capitular ante sus vencedores. En documentos se consignaron sus promesas de fidelidad a Carlos III y la religión católica, el retorno a todas las tributaciones impuestas por los españoles, el compromiso de defender la villa de todo ataque exterior, la entrega de los líderes rebeldes y de sus armas. Una gran parte de las comunidades capitulantes alegaron haber sido sometidas a servidumbre por las comunidades más belicosas de Sica-Sica, Carangas, Pacajes y Challapata, lo que permite presuponer la existencia de fricciones interétnicas entre ellas, vale decir, el resurgimiento de conflictos anteriores al período hispano. ${ }^{52}$

Pasado cierto tiempo, y aunque en Oruro los miembros del Cabildo rebelde expusieran innumerables argumentos para fundamentar la traición primera de los chapetones y la lealtad de los criollos hacia el poder español, las sospechas sobre sus responsabilidades y la necesidad de castigarlos se hizo evidente. Sin embargo, fue la concreción de un nuevo tumulto para las "carnestolendas" de 1783 -que se supuso vinculado al alzamiento de Diego Cristóbal Túpac Amaru - el que precipitó la represión española sobre la villa. ${ }^{53}$

\section{Objetivos, argumentos y relación de fuerzas}

La rebelión estallada el 10 de febrero de 1781 en Oruro, excedió el modelo espontáneo ofrecido por los motines contra el repartimiento, donde usualmente se atacaba la casa del corregidor en un día de fiesta cuando la población era reunida para cobrarles los efectos repartidos, y tampoco responde a las especificidades de una revuelta antifiscal, aunque pueda participar de muchas de sus características. Hemos detectado la existencia de justificaciones ideológicas que planteaban que los amotinados se rebelaron contra los chapetones y los masacraron como autodefensa, pues éstos planeaban asesinarlos. Los testimonios y documentos parecen indicar que el primer objetivo del alzamiento fueron los comerciantes chapetones. El corregidor no estaba en la mira de los rebelados en la primera

52 AGN, Sublevación de Oruro, 1781, leg. 2, exp. 4.

53 A principios de marzo de 178.3, el lunes de Carnestolendas se temió un nuevo alzamiento, pues la plebe en grupos bailaba por las calles, entonando versos provocativos. Unas 300 personas intentaron entrar en la Plaza Mayor pero amenazados por el corregidor se retiraron. Un nuevo intento también fue desbaratado. Los rumores nuevamente señalaron a los Rodríguez como convocantes, mientras este movimiento coincidía con un alzamiento en los cerros de Quispicanchis, promovido por Diego Cristóbal Túpac Amaru. AGN, Sublevación de Oruro, 1781, leg. 1. 
noche de masacre, por cuanto sabedor de los rumores que corrían sobre un complot chapetón, había intentado infructuosamente calmar a los milicianos acuartelados, luego a caballo vio las muchas muertes de chapetones que hacían y si bien trató de que algunos criollos frenaran el alzamiento (Manuel de Herrera haciendo caso omiso le dijo "que ya era tarde..."), tuvo la suerte de salvar su vida cabalgando hacia Cochabamba. ${ }^{54}$

El carácter de "rebelión" estaría dado porque no fue un alzamiento de corta duración, ni estuvo restringido a la villa de Oruro, sino que parecen evidenciarse contactos con comarcas próximas y aún distantes (Arque, Tapacari, Sica-Sica, y. según algunos incluso La Paz o el Cuzco), no estuvo motivado por un estímulo directo ni resultó de fácil control para los españoles. ${ }^{55}$

Testimonios de peninsulares y criollos pro-hispanos señalaron que existía entre los criollos y la plebe rebelada un fuerte sentimiento "antieuropeo", que bien podía implicar la aspiración a librarse del yugo colonial. Se señaló repetidamente que se había vivado a Túpac Amaru y portado sus estandartes durante los primeros días, y que el escudo de armas reales había sido tirado por tierra. Con ese sentido, María Mercedes de la Plaza, viuda de Manuel Antonio Pavía, recuerda que al salir del beaterio donde se había refugiado encontró al capitán Clemente Menacho, quien le preguntó por qué lloraba, y al darle el motivo, él riendo afirmó: - "Vaya Usted, señora, que ahora estamos bien aquí, pues no tenemos quien nos mande". Juan de Dios Rodríguez habría afirmado en un convite en su honor el día de su santo, después que los indios habían sido echados de la villa, que "debía darse gracias a Dios porque había llegado el día de restituirse este reyno a sus verdaderos dueños...”; y Mariano Lasarte, reo de la causa, profirió a gritos el 28 de agosto de 1784, mientras era conducido desde la Real Cárcel de Buenos Aires hasta los calabozos de Oruro, las significativas palabras: “¡Muera Carlos III! ¡Menacho: viva la compañía, los nuestros!". ${ }^{56}$

54 Golte, Repartos y rebeliones.... págs. 139-152; O’Phelan Godoy, Scarlett, "Hacia una tipología y un enfoque alternativo de las revueltas y rebeliones del Perú colonial (siglo XVIII)", en Jahrbuch für Geschichte von Staat, Wirtschaft und Gesellschaft Lateinamerika, vol 21, Colonia, 1984, págs. 130-133; CDIP, doc. 176.

55 Hemos utilizado la tipología de "revuelta" y "rebelión" definida por O’Phelan Godoy, en "Hacia una tipología y un enfoque alternativo...", pág. 128.

56 En el "Diario del Tumulto...", pág. 330, se cita la arenga subversiva de Sebastián Pagador al comienzo de la rebelión. AGN, Sublevación de Oruro, 1781, leg. 1, primer cuaderno; y Sublevación de Oruro, 1781, leg. 4, exp. 11. 
En algunos escritos —especialmente aquellos eclesiásticos- ese antieuropeísmo aparece acompañado o teñido de un cierto contenido mesiánico. Así se observa en un escrito atribuido al vicario doctor Patricio G. Menéndez, considerado uno de los principales ideólogos de esta rebelión, donde afirma que los criollos obtuvieron la victoria aunque no contaban más que con piedras contra las balas de los chapetones, porque "no es maravilla que el fuerte/ todo poderoso Dios/ quando media sinrazón/ castigue con su Justicia/ a aquellos que la proponen/ asistiendo mui proficuo/ a los menos esforzados". Igualmente decía en unos versos refiriéndose a los Rodríguez: "Don Jacinto y Juan de Dios/ ...padecen a Dios juro/ por ser criollos de Oruro/ y que les dio caudal Dios". Con el mismo sentido, la beata María Luisa Sempertegui escribe dos cartas a Sebastián de Segurola, afirmando en una de los chapetones: "no quieren creer que son castigos de Dios por la avaricia, soberbia e ingratitud a sus beneficios, pues olvidándose de su justicia, pusieron la adoración en la plata, en el oro, y en todo lo caduco, sin dar limosna a los pobres, ni hacer templos para el criador, y por eso...murieron assí y se acabaron los caudales". Y en la otra: "...siempre Dios ha estado defendiendo, díganlo las balas de esa noche que no hicieron nada, el haver votado de aquí a los indios tantas veses, el defenderse de los tucumanos, la mortandad de los chuquisaqueños... para que Vd. conosca que el mismo Dios defiende esta Villa". ${ }^{57}$

El "antieuropeísmo" fue la consigna central que permitió la alianza de los indios con los criollos y cholos orureños, alianza que igualmente había sido planteada por Túpac Amaru, de quien un importante sector de los conjurados esperaban estableciese su reinado. Traían los indios un fuerte sentimiento de odio contra el corregidor y sus colaboradores inmediatos, los criollos pro-hispanos, los caciques colaboracionistas, etc., razón por la que masacraron a cuanto chapetón encontraron en la villa, a sus negros esclavos, a unos pocos criollos y cholos, y luego a los caciques Manuel Campoverde y Lope Chungara, porque ambos habían pretendido cobrarles el tributo. ${ }^{58}$

Debido a la abundancia de declaraciones, justificaciones y rumores esparcidos hemos considerado conveniente sintetizar tres versiones co-

57 Anónimo, atribuido al vicario doctor Patricio G. Menéndez, "Lamentable querella de la Villa de Oruro, por la ingratitud de sus hijos, así nacidos de su seno como de los adoptibos", en AGN, Túpac Amaru. Documentos sueltos, s. IX; AGN, Oruro, 1782-1811, s. IX, leg. 2; Frigerio, "Crimen y castigo...”, pág. 73.

58 Cajías, “Los objetivos de...”, pág. 414. 
rrespondientes a las visiones de casta de españoles, criollos e indios, considerando a los cholos como integrando la casta criolla. Vale decir, hemos establecido coincidencias ideológicas relativas a los objetivos e intereses manifiestos de cada casta, y en lo que atañe a su relación con las otras castas. En síntesis:

Los españoles consideraron que a pesar de su benevolencia en habilitaciones y préstamos, se les pagó con la traición, el robo y el asesinato, por cuanto el odio y la ambición reinantes condujeron a la alianza de los criollos y los cholos con los rebeldes tupamaristas.

Los criollos no sólo se sintieron víctimas de un complot chapetón, sino que alegaron haber sido empujados por los indios a la adopción de comportamientos indeseables; no sólo se mostraron como depositarios de la legalidad y el orden frente a la anarquía reinante, sino que disputaron los caudales (los de las Reales Cajas y los robados) a los indios y la plebe mestiza, a la par que trataban de demostrar que su fidelidad a la corona española nunca había flaqueado.

Los indios se sintieron víctimas de los criollos, porque aquéllos los habían convocado para defenderlos y matar chapetones, y luego los arrojaron sin miramientos de Oruro. Cercaron la villa e intentaron asolarla, mientras la propia radicalidad revolucionaria del alzamiento hacía rebasar las consignas tupamaristas, conduciéndolos al intento de repartir haciendas, minas e ingenios de españoles y criollos entre las comunidades campesinas. Al ser vencidos bélicamente por los criollos, muchas comunidades capitularon frente a su hegemonía.

Esta rebelión puede explicarse como una disputa por el poder. A partir del 10 de febrero se concretó una alianza encabezada por los criollos de Oruro, quienes secundados por los cholos, indios yanaconas y forasteros, se levantaron contra el poder español. A partir del día siguiente, comenzaron a entrar multitud de indios de las comunidades cercanas que se integraron a esa alianza aunque pronto discutirían la jefatura criolla. La relación de fuerzas era favorable a la sublevación tupamarista, a la par de su superioridad numérica, por lo que los indios obligaron a los criollos y cholos a adoptar su vestimenta (imponiendo su hegemonía) y sobrepasando directivas de Túpac Amaru comenzaron a atacar propiedades criollas, lo que condujo a una reacción de parte de éstos y a una división en el seno del propio movimiento indígena. El sector más agresivo (las comunidades más pobres, con mayor número de forasteros sin tierras) fue echado de Oruro por una nueva alianza de criollos, cholos y un 
sector conciliador de las comunidades cercanas. Luego se produjo un enfrentamiento entre los criollos y los cholos, por el control de los bienes robados, triunfando los primeros. Frente al ataque de las comunidades más atrasadas (Paria, Sillota y Challacollo), se recompuso la alianza primigenia de criollos y cholos; recién en el tercer ataque se sumarían a ellos los chapetones sobrevivientes indultados, derrotando totalmente la embestida de las comunidades lideradas por la más belicosa y principista de Challapata, junto a Sica-Sica, Carangas y Pacajes. Como la relación de fuerzas comenzaba a tornarse desfavorable para el movimiento tupamarista, comunidades vecinas capitularon durante todo 1781 ante los criollos de Oruro, suponiendo que estos ex-rebeldes serían más compasivos que los despiadados españoles. Apoderados los criollos de los cargos del Cabildo y el control total de la villa, y liderando una alianza relativamente estable con los cholos y los indios capitulados se mantuvieron casi tres años, mientras trataban de recomponer su vinculación al poder español, hasta que éste decidió romper tan peligrosa situación potencialmente proclive a un nuevo alzamiento. ${ }^{59}$

\section{Conclusiones}

Oruro no fue seguramente ajena a ninguna de las causas que motivaron la rebelión general de 1780 en el Alto y Bajo Perú (al tributo y el reparto se añadieron un aumento excesivo de las cargas fiscales y del control burocrático real durante la década de 1770), aunque vivió carac-

59 La relación de fuerzas tornábase desfavorable debido a las numerosas victorias cobradas por la represión española y la división creciente en el seno del movimiento indígena en razón de la pérdida en aumento de aliados por parte de Túpac Amaru como consecuencia de la radicalización del movimiento. Muchos caciques y nobles descendientes de los incas no aceptaron a Túpac Amaru como su líder mesiánico, añadiendo al rechazo étnico (Túpac Amaru era mestizo) sus propios intereses económicos, pues al igual que curas y criollos que vieron atacadas crecientemente sus haciendas, minas e ingenios, no querían perder sus privilegios. Túpac Amaru sería pronto apresado y ejecutado con toda su familia, igual que los hermanos Dámaso y Nicolás Catari, con lo que cambiaría el curso de la rebelión. Poco antes había surgido como líder altoperuano Julián Apasa, llamado Túpac Catari, un indio carente de linaje que acaudillaba comunidades aymaras, quien condujo la rebelión a un enfrentamiento de tipo étnico (persiguiendo a españoles y criollos por igual), compitiendo y hostilizando las tropas tupamaristas, pertenecientes a la etnia quechua. Flores Galindo, "Túpac Amaru y la sublevación de 1780", págs. 271-323; O’Phelan Godoy, Un siglo de rebeliones.... págs. 223-294; Campbell, León G.: "Ideología y faccionalismo durante la gran rebelión", en Steve J. Stern (comp.): Resistencia, rebelión y conciencia campesina en los Andes, siglo XVIII al $X X$. Lima, 1990, págs. 118-140. 
terísticas peculiares por ser uno de los más importantes centros mineros del Alto Perú. La documentación induce a pensar que en ella se añadió una particular coyuntura de falta de liquidez de sus mineros criollos, agravada por el retiro de los auxilios financieros de parte de sus habilitadores españoles, en confluencia con la aparición de una conciencia política vinculada circunstancialmente a la rebelión tupamarista y decidida a enfrentarse al poder colonial español.

Por eso, podemos detectar en Oruro en esta coyuntura la gestación de un incipiente polo de poder criollo, acompañado de la elaboración de una ideología nacionalista criolla, antecedente de la que luego maduraría al calor de las luchas de independencia. Este nacionalismo criollo, de connotaciones urbanas y mineras, posee un fuerte contenido de identidad americana, y aunque surge como opuesto al nacionalismo inca (agrario y mesiánico), resulta simétrico al sustentado por Túpac Amaru, con el que pudo confluir por breve lapso. Contiene incluso un ingrediente mesiánico, en la medida que planteaba un aval divino al accionar criollo, aunque nunca con las características extremas del mesianismo inca, que atribuía a Túpac Amaru las propiedades del mito de Inkarrí, a las que se añadían sincréticamente los poderes de Jesucristo.

Por lo tanto reconocemos a los criollos orureños una dinámica proto-independentista, sustentada en el poder económico, político y militar de los hermanos Rodríguez de Herrera y otros criollos asociados, quienes tejieron una intrincada trama de relaciones personales y económicas de ancha base social (incluía mestizos, cholos, mulatos e indios), que les permitió participar y utilizar con fines propios la gran rebelión campesina india en cuanto se refería a derrocar el poder colonial español, y luego enfrentarla por la notoria divergencia de objetivos que los separaba.

La actitud conspiradora de los criollos era muy antigua, manteniéndose latente aunque manifiesta en muchas disidencias menores, logrando algunos avances sobre el poder español (control de los principales cargos del Cabildo), siendo el detonante la penosa coyuntura que se abrió en la década de 1770 (fuertes presiones fiscales, aumento del control burocrático real, falta de liquidez y empobrecimiento generalizado), compeliéndolos a sublevarse y confluir con la rebelión india.

Otra característica de este nacionalismo criollo sería la elaboración de variadas justificaciones ideológicas para su propio accionar (sentirse víctimas inocentes de un complot chapetón), aunque la carencia de un programa independentista sería causa primera de esa alternancia ambigua 
entre los dos polos enfrentados (españoles e indios), de esa ambivalencia que no sólo implicaría la alianza y enfrentamiento subsiguiente con los indios a la par del fingir seguir siendo leales vasallos de la corona española, sino incluso la oposición de los intereses individuales caudillistas con los de casta. Por eso se suceden codiciosos enfrentamientos por los caudales de las Reales Cajas entre criollos e indios.

Si en un principio los criollos y cholos orureños pudieron coincidir con las democráticas consignas de Túpac Amaru fue porque el sueño de un resurgimiento neo-inca fue una idea políticamente irresistible para amplios sectores sociales, aunque pronto entraron en contradicción con la dinámica de las masas campesinas indias que objetivamente plantearon crecientemente una revolución social contra todo símbolo de opresión y contra todo privilegio económico.

Justamente fueron los privilegios económicos, políticos y militares detentados por los criollos más acaudalados de Oruro y en menor medida por el resto, los que conspiraron desde un principio contra toda posible alianza. Las maniobras para conservar su liderazgo en la coalición con los indios y cholos, y luego incluso frente a los españoles, aunque dándoles vivas muestras de su colaboración y supuesta lealtad, configuran esa dinámica proto-independentista que los españoles intentaron destruir en germen al someterlos a una larga y penosa causa judicial. 
(c) Consejo Superior de Investigaciones Científicas

http://estudiosamericanos.revistas.csic.es Licencia Creative Commons 3.0 España (by-nc) 


\title{
Apéndice documental
}

\author{
PRINCIPALES REOS DE LA REBELIÓN DE ORURO * \\ (Procedencia, edad, ocupación, bienes propios, \\ embargados, confiscados)
}

- José Mariano Azurduy Lasarte: vecino y natural de Oruro, 32 años en 1784, casado con María Francisca Goya (también rea de la causa), ropavejero con tienda pública en la plaza de Oruro, alférez de Milicias en la compañía de Clemente Menacho; le fue embargada su casa con sus muebles, efectos de Castilla y de la tierra de la tienda y mercería que poseía.

- Antonio Quirós: natural de la provincia de Cochabamba, vecino de Oruro desde hacía 20 años, 46 años en 1784, casado, minero de oficio, deudor del Ramo del Azogue y de Temporalidades; se le embargaron bienes muebles y una partida de alhajas de plata labrada; poseía una mina en el Cerro de San Cristóbal ( 1/4 legua de Oruro) que no fue embargada.

- Nicolás Iriarte: natural de la villa de Cochabamba y vecino de Oruro desde hacía veinte años, 42 años en 1784, comerciante con tienda de ropa de Castilla y de la tierra, deudor de la Real Hacienda, alférez de Milicias antes del virreinato y capitán; se le embargaron fincas, efectos de Castilla y de la tierra de su tienda, y alhajas de oro y plata; era deudor del Ramo del Azogue, por lo que seguramente también sería minero.

- Casimiro Delgado: natural del Curato de Paria y vecino hacía cincuenta años de Oruro, 70 años en 1784, casado, de oficio comerciante de aguardientes y panadero; se le embargaron casas y bienes muebles, alhajas de oro y plata, y la hacienda "Laramapugyo", en el partido de Sica-Sica, provincia de La Paz, con ganados mayores y menores.

- Isidro de la Riva: natural y vecino de la Villa de Oruro, 60 años en 1784, casado con Catalina Rodríguez de Herrera (hermana de Jacinto, Juan de Dios e Isidro), minero y azoguero de oficio, fue capitán de Milicias de una compañía extinguida, poseía ingenios en la Ribera Ayo-Ayo, el mismo lugar de donde provenía Túpac Catari a quien se lo vinculaba, y una india por comadre; le embargaron una casa con oficinas y un trapiche con una casa próxima, bienes muebles, ajuar y ropa de uso; le confiscaron por deudas al Ramo del Azogue alhajas de oro y plata por valor de 346 pesos, 1/2 real; tenía firmada una hipoteca general de sus bienes a favor de Juan de Dios Rodríguez por adeudarle 64.000 pesos. Fue alcalde de Oruro después de la rebelión de 1781 .

* AGN, Sublevación de Oruro, 1781, leg. 1, exp. 12 y leg. 4, exp. 4; AGN, Hacienda, 1780-18(14, leg. 27, exp. 680; Tribunales, leg. 36, exp. 12. 
- Juan Gualberto Mejía: natural de Chayanta y vecino de Oruro desde 1780, 34 años en 1784, casado, abogado de la Real Audiencia de Charcas, poseía una tienda y un balcón sobre la plaza; se le embargaron una casa y bienes muebles, papeles y librería, alhajas de oro y plata, e importante cantidad de objetos suntuarios y plata labrada.

- Clemente Menacho: natural de Lima y vecino de Oruro desde hacía veinticuatro años, mulato, minero y azoguero de oficio, casado con María Quirós (hermana de Antonio Quirós y rea de la causa), comerciante y hacendado, capitán de Milicias en 1781 y procurador general en 1782; se le embargaron bienes de una tienda de mercería que poseía; la mina "El Prado" en los cerros de Oruro; el ingenio de Cervantes, ubicado en la Ribera de Sepulturas, con aperos y materiales; la hacienda de "Cullcupampa" en el partido de Arque, provincia de Cochabamba; algunas casas que poseía en Arque, que fueron rematadas junto a un esclavo y mulas para pagar sus deudas en el Ramo del Azogue.

- Felipe Aseñas: vecino y natural de Oruro, 67 años en 1784, de oficio fundidor, ensayador y balanzario; se le embargó el trapiche "Calpamayo", en proximidades de Oruro.

- Pedro Ascuas: natural y vecino de Oruro, 29 años en 1784, comerciante de coca y aguardientes, poseía dos tiendas bien provistas que no fueron embargadas; le embargaron la hacienda "Uputañe", en la provincia de Cochabamba.

- Sebastián Crespo: natural de la provincia de Cochabamba y vecino de SicaSica, provincia de La Paz, desde hacía veintitrés años, 42 años en 1784, comerciante de oficio y capitán graduado de Ejército; le embargaron la hacienda de "Chilcani", en el partido de Sica-Sica.

- Francisco Javier de Velasco: natural de la ciudad de La Plata, sin domicilio fijo por ser comerciante de oficio y capitán graduado de Ejército, 25 años en 1784; se le embargaron bienes de poca consideración.

- Mariano Bernal y Lira: vecino y natural de Oruro, 38 años en 1784, sacerdote, abogado graduado en la Universidad de Charcas, hablaba el idioma aymara; sirvió como teniente de Cura en Challacollo por 8 años, seis meses en Corque y un mes en Challapata; en tiempos de la rebelión orureña fue - con título expedido por el vicario Menéndez- como teniente de cura al pueblo de Paria; no se le embargaron bienes de importancia.

- Patricio Gabriel Menéndez: natural de Potosí, abogado de la Real Audiencia de Charcas, doctor en Teología, comisario del Santo Oficio de la Inquisición, cura rector de la Iglesia Matriz de Oruro y vicario juez eclesiástico de la villa; no se le embargaron bienes de importancia.

- Miguel Portilla: comerciante con tienda surtida en efectos de Castilla, que fue embargada. Murió a poco de ser apresado en 1784, al desbocarse la mula sobre la que estaba amarrado mientras intentaba huir.

- Manuel de Herrera: natural de Oruro, 67 años en 1784, minero y azoguero de oficio, tuvo cargos en el Cabildo orureño desde la década de 1740 ge- 
neralmente como alcalde provincial y regidor, alcalde de 1." y 2." voto; coregidor de Oruro en 1752 aunque fue prontamente destituido y corregidor de Paria en 1784, poseía la mina del "Espíritu Santo"; tenía el título de gobernador de Chucuito y tenía firmada una hipoteca general sobre todos sus bienes a favor de Juan de Dios Rodríguez; fue alcalde de $1 .^{\text {er }}$ voto en 1782 ; se le embargaron su casa y bienes muebles, ropa de uso, dos cabezas de ingenio llamadas "San José de Buenavista", ubicadas en la Ribera de Sepulturas; murió en Potosí a poco de ser apresado en 1784.

- Diego Antonio Flores: natural del reino de Chile y vecino de Oruro desde hacía 26 años, minero de oficio, casado con una hija de José Galleguillos, alférez real desde hacía quince años; también sirvió como alcalde, síndico, procurador general y como justicia mayor durante la expulsión de los jesuitas; tenía un gran ingenio en Sora-Sora y otros bienes que fueron embargados cuando en 1776 le iniciaron juicio por sus deudas al Ramo de Correos -que administraba - y al Ramo del Azogue, continuando el juicio durante los años de la rebelión; en 1784 no poseía bienes propios, salvo los que figuraban a nombre de su mujer, María Josefa Galleguillos: un ingenio en Sora-Sora, con aperos; le fueron confiscadas alhajas de oro y plata por sus deudas al Ramo del Azogue.

- Bernardino Ibáñez: natural de Arequipa y vecino de Oruro desde hacía nueve años, 37 años en 1784, sombrerero de oficio; se le embargaron bienes muebles de poca consideración, y piezas de plata labrada que pertenecían a terceros y les fueron devueltas.

- Bernabé Antonio Pineda: natural de Oruro, 43 años en 1784, casado, comerciante de la coca de los Yungas; administrador, cajero y apoderado de Jacinto Rodríguez; se le embargaron bienes muebles, ropa y ajuar, y cierta cantidad de plata que como pertenecía a su mujer, a ella fue entregada.

- Jacinto Rodríguez de Herrera: natural de Oruro, 48 años en 1784, viudo, minero y azoguero de oficio, regidor decano de Oruro, fue por muchos años alcalde ordinario, teniente coronel de las milicias de Oruro desde 1771, y justicia mayor después de la rebelión de 1781; deudor del Ramo del Azogue; poseía minas en Corocoro, la mina del Cerro de la Colorada, una mina de oro en arrendamiento y otra despoblada, las tierras de Cheysola, las de Larma, la estancia del Cerro de Sillota, la de "Untutaamaia", la de "Pucara" y el ingenio "Muy Diminuto"; se le embargaron cuatro casas en la villa, esclavos, la mina de "Todos los santos" en los cerros orureños y un trapiche cercano, las haciendas de "Larma" y "Vilacara", en el partido de Pacajes, provincia de La Paz.

- Juan de Dios Rodríguez de Herrera: natural de Oruro, 50 años en 1784, soltero, minero y azoguero de oficio, deudor del Ramo del Azogue y de Temporalidades, fue alcalde ordinario muchos años, regidor, alcalde provincial y procurador de Oruro, coronel de las milicias urbanas desde 1778, y justicia mayor de Paria después de la rebelión de 1781; aparece como asociado 
al cobro de un repartimiento efectuado por el corregidor interino Tomás Bentura Ayarza en 1779; poseía varias minas que no fueron embargadas, entre ellas una de cobre granalla con la que proveía a la corona 130 quintales al año, partida que fue suspendida en 1777; poseía el socavón de San Antonio de Abicaia, el socavón del mineral de oro de Toraca, minas en el Mineral de Antequera, las tierras de Aramarca; se le embargaron varias fincas y esclavos, el ingenio "San Agustín Alantaña Chico" y el ingenio "Guayguaci", en la Ribera de Sepulturas, tres cabezas de ingenio y la hacienda de "Pazña" en el partido de Paria, las haciendas "Yarbiri", "Cusimolino", "Colcha y Taconi", "Guailla", en Colcha, provincia de Cochabamba, la hacienda "Vinto" en Cochabamba, las haciendas "Tolapalca", "Guañapasto" y la del cerro Sillota (de la que era socio de su hermano Jacinto), en las proximidades de Oruro. Sus bienes incluían numerosas obligaciones de terceros a su favor, actuando como aviador, y al parecer también como prestamista de dinero. 